\title{
Photovoltaic Power System with MPPT Functionality for a Small-Size Electric Vehicle
}

\author{
Jianming Xu, ${ }^{1}$ Longyun Kang, ${ }^{2}$ Changyi Zhong, ${ }^{2}$ and Binggang Cao ${ }^{1}$ \\ ${ }^{1}$ Institute of Mechanical Engineering, Xian Jiaotong University, Xi'an 710049, China \\ ${ }^{2}$ Guangdong Key Laboratory of Clean Energy Technology, School of Electric Power, South China University of Technology, \\ Guangzhou 510640, China
}

Correspondence should be addressed to Jianming Xu; andyjm3@gmail.com

Received 7 December 2013; Accepted 20 April 2014; Published 18 May 2014

Academic Editor: Roel van De Krol

Copyright (C) 2014 Jianming Xu et al. This is an open access article distributed under the Creative Commons Attribution License, which permits unrestricted use, distribution, and reproduction in any medium, provided the original work is properly cited.

\begin{abstract}
Electric vehicles are recognized as the best replacement of petrol vehicles in the future. However, there are several problems hampering their development, such as the short life span of batteries, poor performance of start-up, and a short driving range. In order to resolve these problems, a hybrid power system based on photovoltaic (PV) cells, supercapacitors, and batteries is proposed. This paper focuses on PV cells using a maximum power point track (MPPT) system based on a BUCK chopper circuit. Moreover, a novel MPPT algorithm named sectional variable step climbing (SVSC) algorithm was proposed. To validate the proposed system, two main experiments have been done. The first experiment showed that the MPP of PV cells was tracked perfectly by use of this photovoltaic power system. The second one showed that the efficiency of SVSC was higher than two existing MPPT methods, the climbing algorithm and the open-circuit voltage (OCV) algorithm.
\end{abstract}

\section{Introduction}

The energy crisis and pollution problems in the long term continue to worry vehicle manufacturers. In order to resolve the negative problems caused by automobiles, researching and applying new alternative energy in the field of automobile are attracting people's attention. Electric vehicles (EVs), fuel cell vehicles, and solar vehicles are emerging on a large scale.

Unlike nonrenewable energy resources such as fossil fuels, photovoltaic (PV) power provides important opportunities for energy efficiency. However, although it is inexhaustible and clean, some disadvantages exist, such as low transfer efficiency and low power density, while intermittent and expensive prices still limit a large-scale application of solar energy. Research on how to improve the transfer efficiency of PV power systems is now becoming popular. A photovoltaic pulse charger using high-frequency pulse trains for charging a lead-acid battery is proposed in [1]. This system can not only explore the charging behavior with maximum power point tracking (MPPT) but also delay sulfating crystallization on the electrode pores of the battery to prolong battery life. Woo-Young Choi designed a high efficiency PV panel integrated power conditioning system by using a high efficiency step-up DC-DC converter [2]. This converter achieves a high efficiency of $96.0 \%$. Yang with his team from Zhejiang University, China, built a $2 \mathrm{~kW}$ photovoltaic power system that employs a ZVT-interleaved boost converter with winding-coupled inductors and activeclamp circuits as the first power-processing stage [3]. The researchers in [4-8] are focused on high efficiency converters, devices which are indispensable elements in a solar energy harvesting system. PV cells matched with another one or two power sources are also a good choice. Wind-solar hybrid power systems may be the most common way [9-12]. In [13] photovoltaic/wind/battery/fuel cell hybrid power systems were designed for powering a mobile off-grid platform. Kazem and Khatib proposed a method for determining the optimal sizes of PV arrays, wind turbines, diesel generators, and storage batteries installed in a building's integrated system [14].

Independent of using one or more power sources, MPPT systems are an indispensable part of a photovoltaic power system. Due to the nonlinear nature of photovoltaic energy, it requires the use of an intermediate converter implementing 


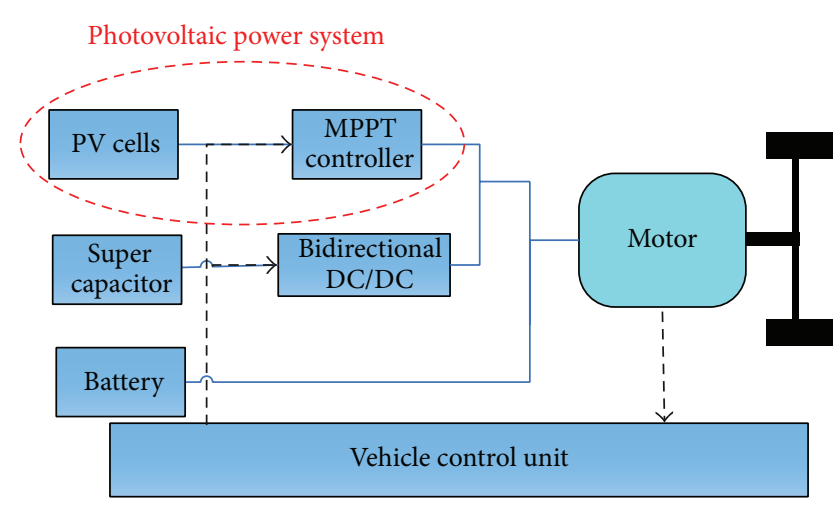

(a)

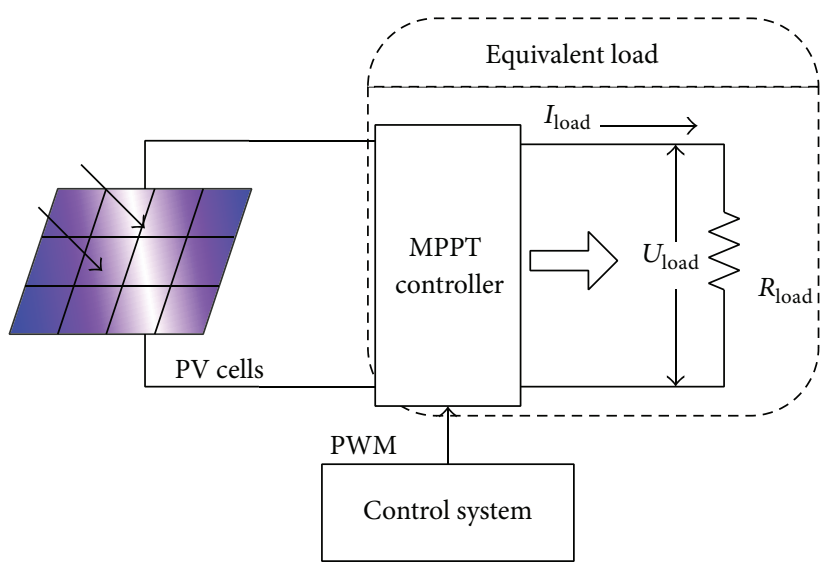

(b)

FIGURE 1: (a) The structure of hybrid power system. (b) The structure of photovoltaic power system.

a control algorithm to operate the PV cells at their MPP under different environmental conditions. Various MPPT methods, such as the perturbation and observation method $[15,16]$, the incremental conductance method [17], the Hillclimbing method [18], and the open-circuit voltage method [19], are proposed. Some intelligence algorithms such as fuzzy control, artificial neural networks, and genetic algorithms are also used for MPPT system. Reference [20] proposed an artificial neural network-based MPPT algorithm optimized with a genetic algorithm implemented in a stand-alone PV system with a direct-coupled induction motor drive. Using that algorithm, the response time was smaller and oscillations around the MPP were reduced to obtain maximal power yield in the steady state. Mahamudul et al. from University of Malaya proposed a novel modeling technique of PV modules with a fuzzy logic based MPPT algorithm and boost converter [21].

In the present paper, a proposal is presented for a photovoltaic power system used in a small-size electric Golf cart, which contains three power sources that are PV cells, super capacitor, and battery. The hardware circuit of the system was designed and built using an MPPT controller and some secondary circuits such as isolated drive circuits, assistant power circuits, and peripheral circuits of DSP. Moreover, a novel MPPT algorithm called "sectional variable step climbing" (SVSC) algorithm is proposed. The experimental results show that the MPP of PV cells is tracked perfectly and that the SVSC algorithm achieved a higher efficiency.

\section{System Description and Modeling}

2.1. Overall Structure of the System. The overall structure of the hybrid power system is shown in Figure 1(a). Three power sources are in parallel with each other and then switched in the $\mathrm{DC}$ bus. The part in the red ellipse is the photovoltaic power system, which is the key innovation of this paper. The detailed structure is shown in Figure 1(b). This system is made up of PV cells and MPPT controllers that connect PV cells with the load and a control system based on DSP.

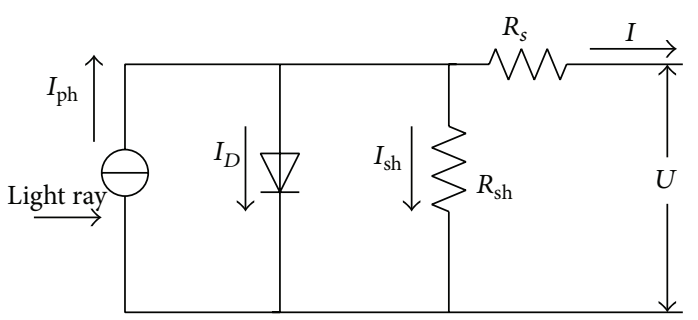

FIGURE 2: PV cells equivalent circuit.

2.2. Photovoltaic Cell Modeling. The output characteristic of PV cells could be expressed by a voltage-current $(I-V)$ characteristic. The $I-V$ characteristic changes along with the solar radiation intensity $(S)$ and temperature $(T)$; that is $I=$ $f(V, S, T)$. When light intensity is constant, a PV cell could be a constant-current source. The equivalent circuit of a PV cell is shown in Figure 2 [22]. Here, $I_{\mathrm{ph}}$ is the photo-generated current, $I_{D}$ is the leakage current of the diode, $R_{\mathrm{sh}}$ is an equivalent shunt resistance, and $R_{s}$ is an equivalent series resistance. As per Kirchhoff's current law, the relationship of the currents can be described as

$$
I=I_{\mathrm{ph}}-I_{D}-I_{\mathrm{sh}}
$$

where

$$
I_{D}=I_{0}\left(e^{q U /(A k T)}-1\right) .
$$

$I_{0}$ is the reverse saturation current intensity of the diode, $q$ is the electronic charge, $k$ is Boltzmann's constant, and $T$ is temperature in Kelvin.

As per Kirchhoff's voltage law and Ohm's law, the output voltage of the PV cell plus the voltage of the equivalent series resistance is equal to the voltage of the equivalent shunt resistance, so $I_{\mathrm{sh}}$ can be described as

$$
I_{\mathrm{sh}}=\frac{\left(U+I R_{s}\right)}{R_{\mathrm{sh}}} .
$$




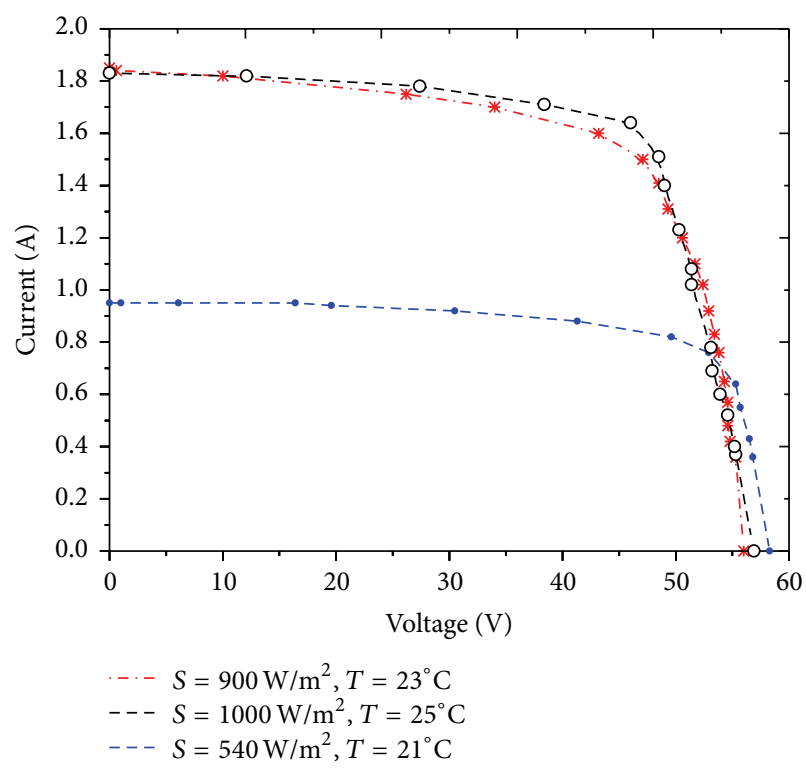

(a)

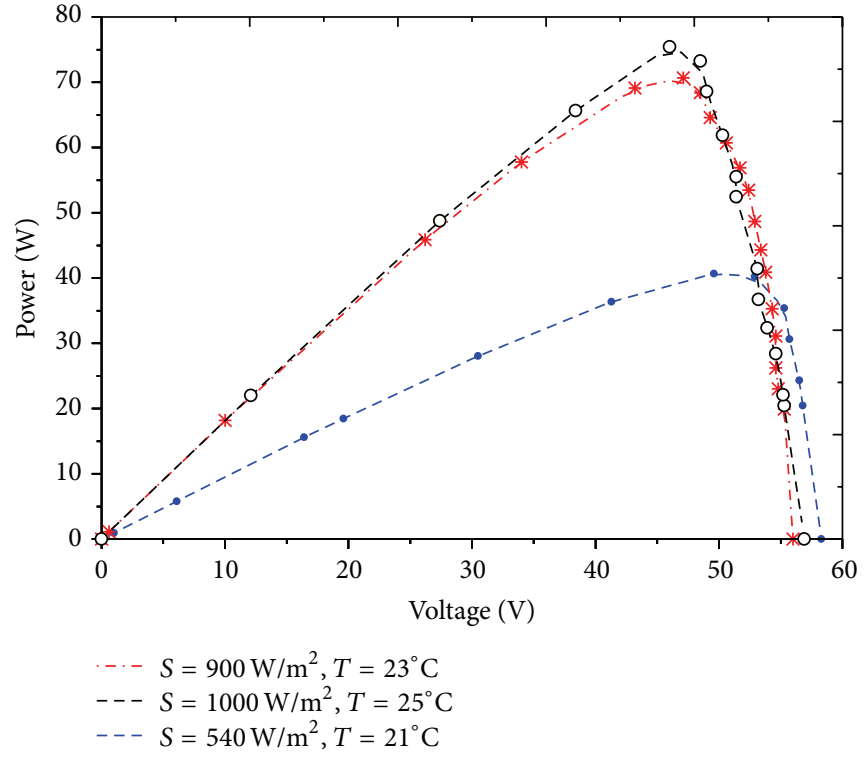

(b)

Figure 3: (a) $I-V$ characteristic curve under different conditions. (b) $P-V$ characteristic curve under different conditions.

According to (1), (2), and (3),

$$
I=I_{\mathrm{ph}}-I_{0}\left(e^{q\left(U+I R_{s}\right) / A k T}-1\right)-\frac{U+I R_{s}}{R_{\mathrm{sh}}} .
$$

The parameters of PV panel used for the power system are shown in Table 1.

The $I-V$ and $P-V$ characteristics of the PV panel were tested under different solar radiation intensities and temperatures. The curves are shown as in Figure 3. Here, $S$ is measured by using a TBQ-2 pyranometer to measure the total solar radiation intensity from 0.3 to 3.2 micron. Figure 3(a) shows the open-circuit voltage and short-circuit current of the PV panel clearly. Each of the curves in Figure 3(b) has a maximum power point. This point changes along with the specific conditions. In order to make sure that the output power of the PV cells could track this point, MPPT is required.

Since the value of $I_{\mathrm{ph}}, R_{\mathrm{sh}}$, and $R_{s}$ is difficult to fix, the PV cell's model can be simplified based on open-circuit voltage, short-circuit current, voltage of MPP, and current of the MPP.

According to (4), when $I=0$, the equation can be described as

$$
0=I_{\mathrm{ph}}-I_{0}\left(e^{q U_{\mathrm{open}} / A k T}-1\right)-\frac{U_{\mathrm{open}}}{R_{\mathrm{sh}}},
$$

where $U_{\text {open }}$ is the open-circuit voltage.

If $U=0$, (4) can be described as

$$
I_{\text {short }}=I_{\mathrm{ph}}-I_{0}\left(e^{q I_{\text {short }} R_{s} / A k T}-1\right)-\frac{I_{\text {short }} R_{s}}{R_{\text {sh }}},
$$

where $I_{\text {short }}$ is the short-circuit current.
TABle 1: Parameters of PV panel.

\begin{tabular}{lc}
\hline Item/unit & Value \\
\hline Standard testing conditions $/ \mathrm{W} / \mathrm{m}^{2} / 25^{\circ} \mathrm{C}$ & 1000 \\
Voltage of MPP/V & 48 \\
Current of MPP/A & 2.75 \\
Open-circuit voltage/V & 60 \\
Short-circuit current/A & 3.1 \\
Panel area/m ${ }^{2}$ & 1.008 \\
PV cells transfer efficiency/\% & 13.2 \\
Weight/kg & 2.78 \\
\hline
\end{tabular}

If the output power of $\mathrm{PV}$ cells is at the point of maximum power, $d P / d U=0$, and making an assumption that $R_{\mathrm{sh}} \gg R_{s}$ so

$$
\left(1+\frac{q U_{\text {mppt }}}{A k T}\right) e^{q U_{\text {mppt }} / A k T}=\frac{I_{\mathrm{ph}}}{I_{0}}+1,
$$

where $U_{\mathrm{mppt}}$ and $I_{\mathrm{mppt}}$ are the voltage and current of MPP.

Above all, the engineering model of PV cells can be described as follows:

$$
\begin{aligned}
I=I_{\text {short }} & {\left[1-\left(1-\frac{I_{\text {mppt }}}{I_{\text {short }}}\right)\right.} \\
& \left.\times e^{-U_{\text {mppt }} /\left(U_{\text {open }}\left(\left(U_{\text {mppt }} /\left(U_{\text {open }}-1\right)\right) / \ln \left(1-I_{\text {mppt }} / I_{\text {short }}\right)\right)\right)}\right] \\
\times & {\left[e^{U /\left(U_{\text {open }}\left(\left(U_{\text {mppt }} /\left(U_{\text {open }}-1\right)\right) / \ln \left(1-I_{\text {mppt }} / I_{\text {short }}\right)\right)\right.}-1\right] }
\end{aligned}
$$

Therefore, the model of the PV cells is shown in Figure 4 under standard testing conditions. 


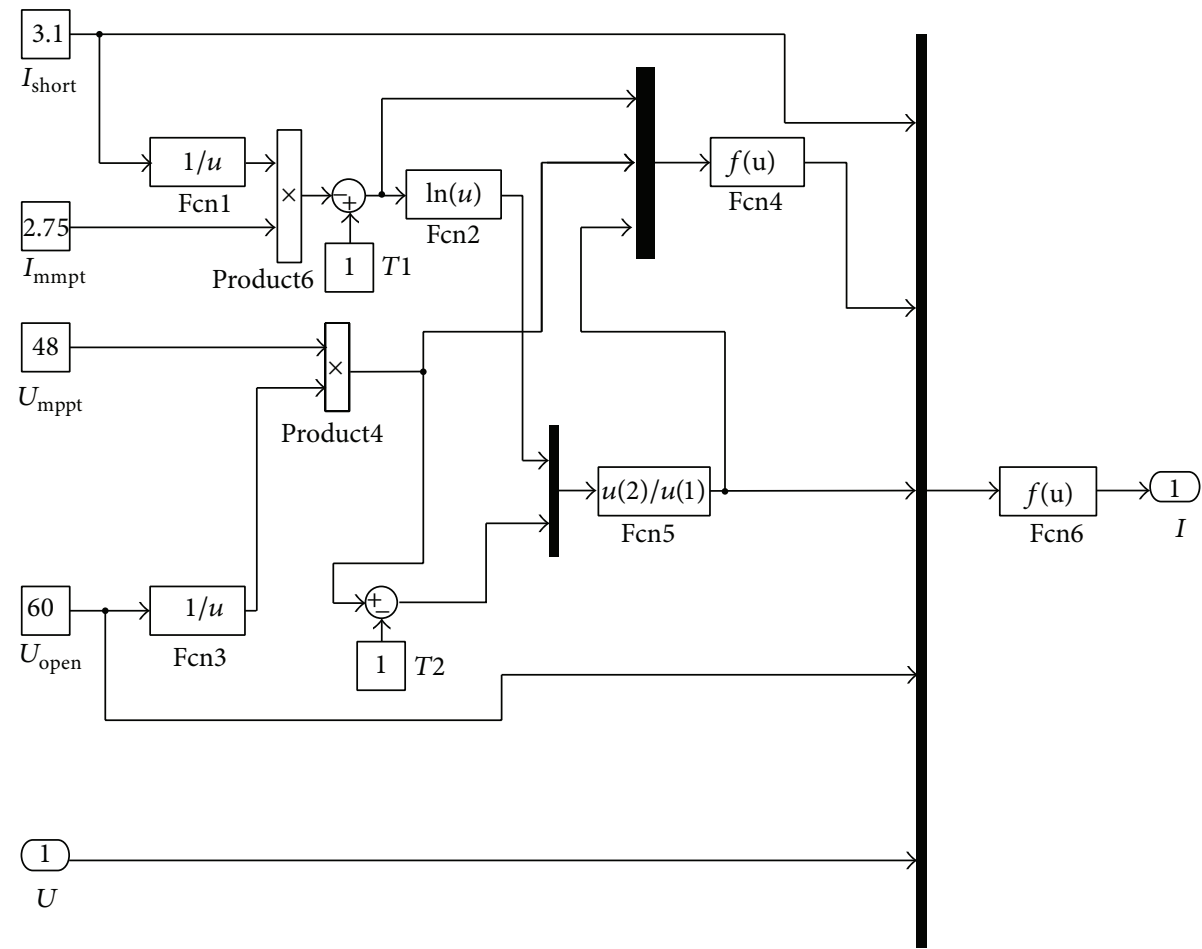

Figure 4: PV cells' model.

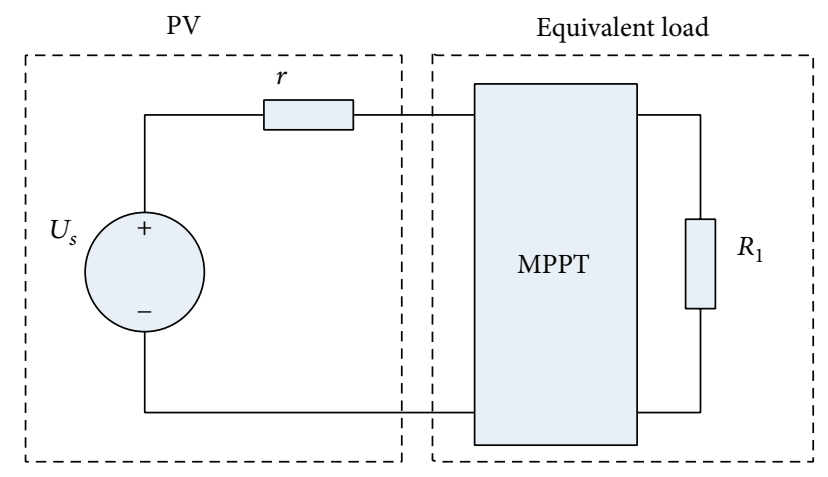

Figure 5: Equivalent model of PV and load.

2.3. MPPT System. Figure 3 shows that the output voltage and current of PV cells are changed along with the ambient temperature and illumination intensity, and under a certain condition there is only one MPP if the surface of the $\mathrm{PV}$ panel is not in shadow. According to the structure of the photovoltaic power system in Figure 1, the actual load, together with MPPT controller, can be recognized as an equivalent load, as shown in Figure 5 . Here, $U_{s}$ is the voltage of PV cells, $r$ is the essential resistance of PV cells, and $R_{1}$ is the resistance of the equivalent load. The power of $R_{1}$ is

$$
P_{1}=I^{2} R_{1}=\left(\frac{U_{S}}{r+R_{1}}\right)^{2} R_{1} .
$$

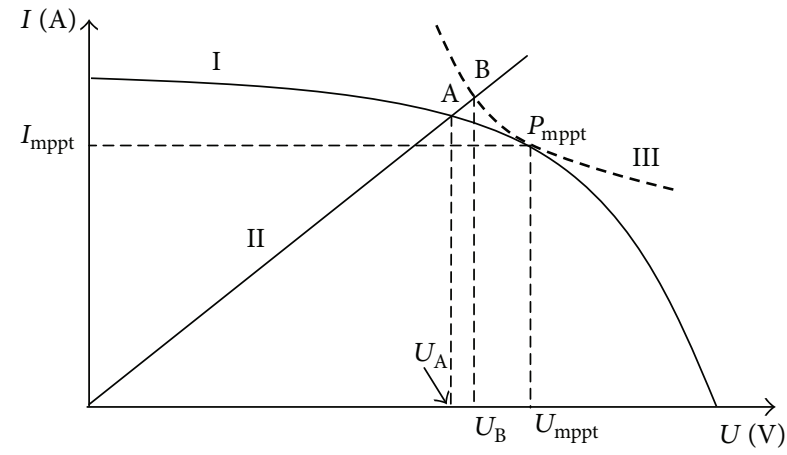

FIgURE 6: Process of tracking MPP.

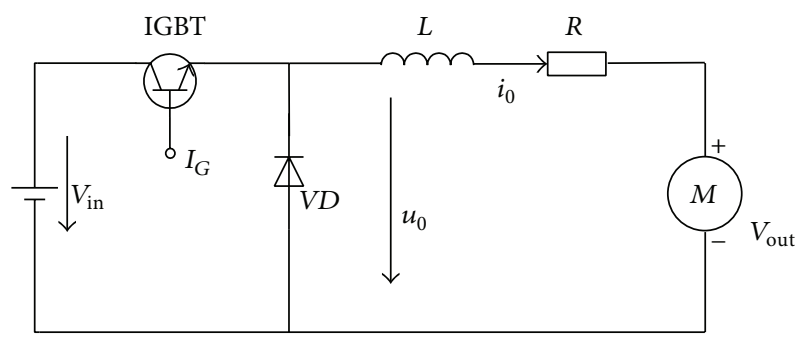

FIGURE 7: BUCK chopper circuit topology.

After taking the derivative with respect to $R_{1}$, (9) becomes

$$
\frac{d P_{1}}{d R_{1}}=U_{S}^{2} \frac{r-R_{1}}{\left(r+R_{1}\right)^{3}} .
$$




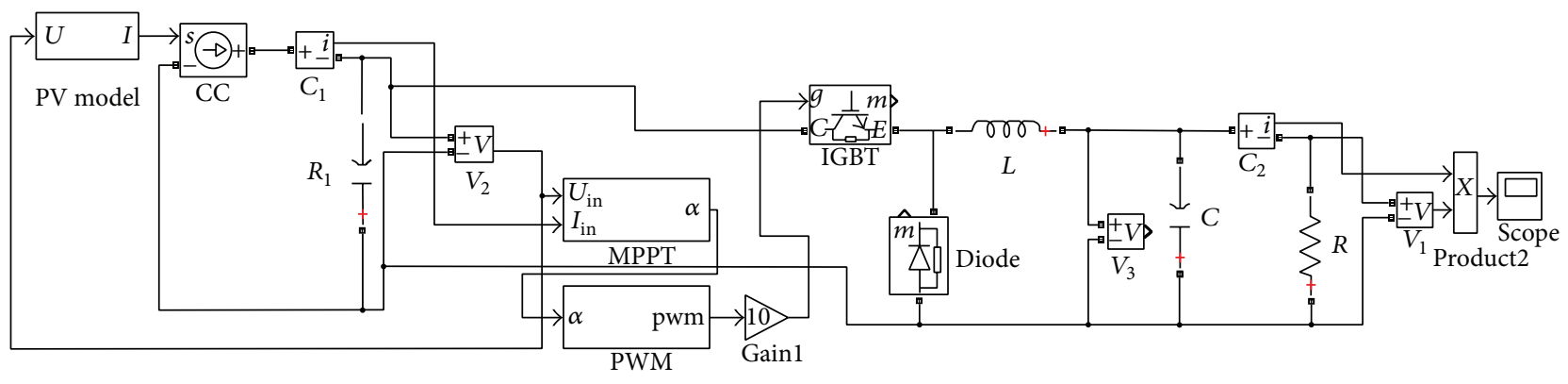

Figure 8: MPPT controller model.

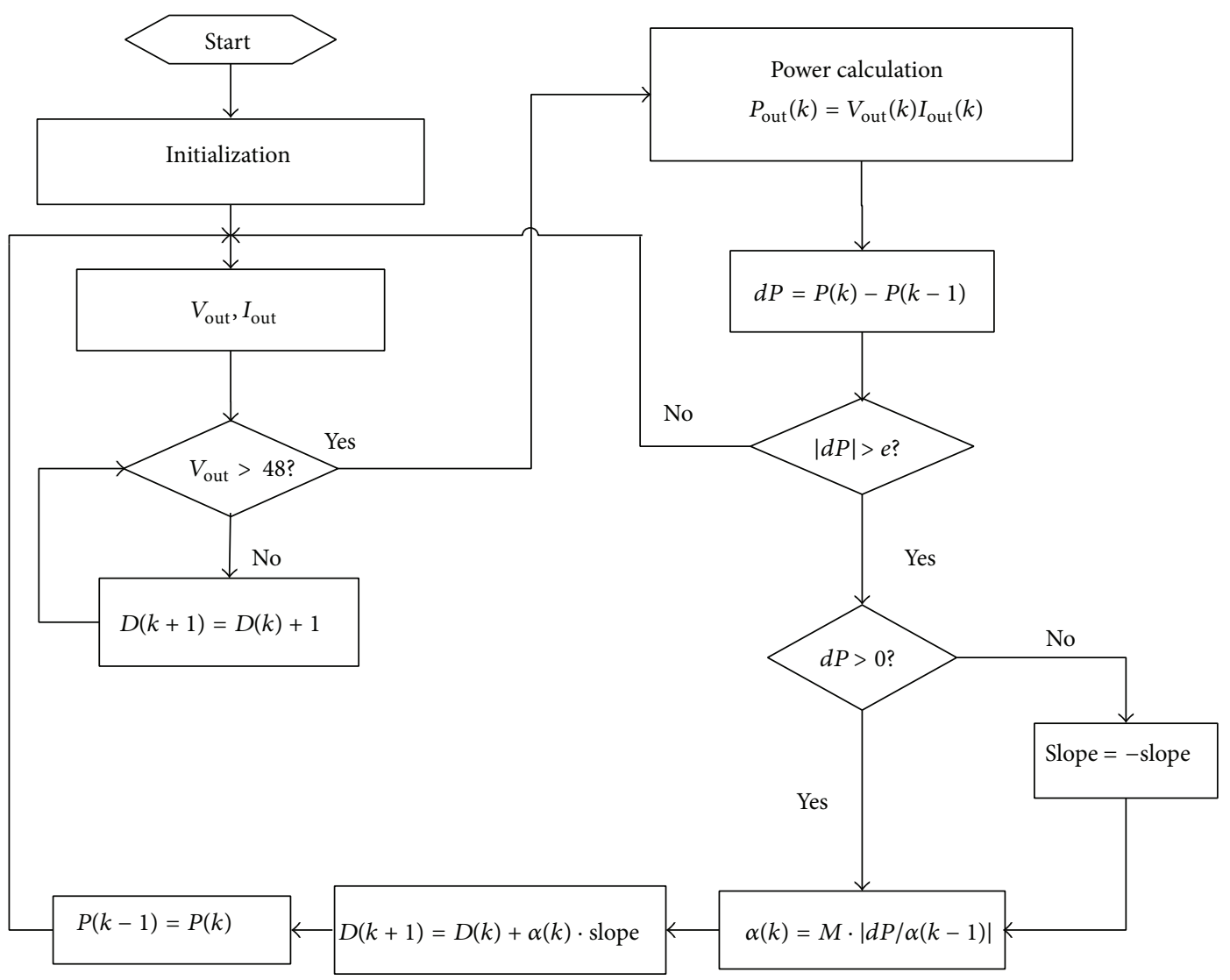

FIGURE 9: Flow chart of control strategy for MPPT.

When $r=R_{1}$, then $d P_{1} / d R_{1}=0$, so $P_{1}$ is the maximum. In fact, $r$ changes along with specific conditions. In order to track the MPP, an MPPT controller, which is actually a $\mathrm{DC} / \mathrm{DC}$ converter, is added between the PV and the actual load. The principle of the MPPT system is that the impedance of the equivalent load changes by changing the duty cycle of the DC/DC converter so that it can track the change of $r$.

Figure 6 describes how to track the MPP more intuitively. Curve I is the $I-U$ characteristic curve of PV cells. Curve II is the $I-U$ characteristic curve of the actual load. The crossing point A is the working point of PV cells. Curve III is the maximum power curve of the PV cells. If the working point A does not coincide with $P_{\text {mppt }}$, it means that the equivalent load does not match the essential resistance of the PV cells. It needs to change the voltage from $U_{\mathrm{A}}$ to $U_{\mathrm{B}}$ and the working point $\mathrm{B}$ is now on the maximum power curve.

The main power circuit of MPPT used in this power system is a BUCK chopper circuit (Figure 7). The conclusion of the BUCK circuit is

$$
V_{\text {out }}=D V_{\text {in }} \text {, }
$$

where $V_{\text {in }}$ and $V_{\text {out }}$ are the input and output voltages and $D$ is the duty cycle. It is assumed that the circuit loss is neglected.

The output power should equal the input power:

$$
V_{\text {in }} I_{\text {in }}=V_{\text {out }} I_{\text {out }}
$$




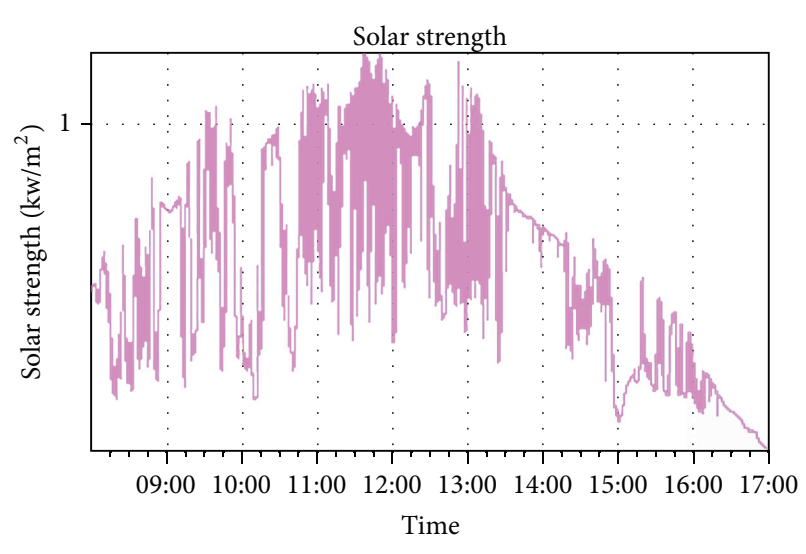

(a) Solar strength rapidly changing

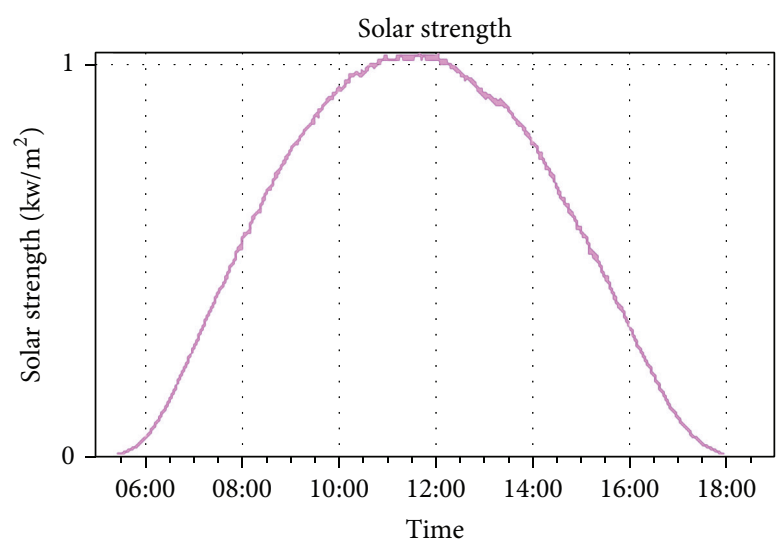

(b) Solar strength in a sunny day

FIGURE 10: Solar strength under different conditions.

Thus,

$$
D I_{\text {out }}=I_{\text {in }}
$$

Considering (12), (14) becomes

$$
R_{\text {in }}=\left(\frac{1}{D}-1\right) R_{\text {out }}
$$

Equation (14) shows that if $R_{\text {out }}$ is constant, $D$ is inversely proportional to $R_{\text {in }}$. By changing $D$ of the BUCK circuit, $R_{\text {in }}$ matches $r$ and the MPP of the PV cells is tracked.

Based on the analysis above, the model of MPPT controller is built as shown in Figure 8 so that the size of electronic components such as IGBT, inductance, and diode can be set to a reasonable value.

\section{Control Strategy of MPPT}

As mentioned in Section 1, because the applications of solar energy are expanding, the development of MPPT technology is increasing in recent years. Lots of novel MPPT methods have emerged, such as the constant voltage tracking (CVT), perturbation and observation ( $\mathrm{P} \& \mathrm{O})$, and incremental conductance algorithms, the Hill-climbing method, the opencircuit voltage (OCV) method, and so forth. This paper proposes a novel MPPT algorithm called the "sectional variable step climbing algorithm" (SVSC). This algorithm is proposed based on the traditional climbing algorithm. The flow chart of SVSC is shown in Figure 9, where $V_{\text {out }}$ and $I_{\text {out }}$ are the output voltage and current of PVs, $P_{\text {out }}$ is the output power of the PVs, $d P$ is the change of power, $D$ is the duty cycle, $a(k)$ is the adjustment of duty cycle step, slope is the sign bit of $a$ with value " 1 " or " -1 " and represents the directional change of step, $M$ is the constant which controls the range of step variation and represents the flexibility of system, and $e$ is a minimum value which is determined by precision and characteristics of the actual system.

The workflow of the system is that after initialization the controller senses the signals of PVs' output voltage and current and then compares the voltage with $48 \mathrm{~V}$. If lower than
$48 \mathrm{~V}$, the controller keeps adjusting the duty cycle until it is higher than $48 \mathrm{~V}$ so that it can charge the batteries. Then it calculates the output power and the change of power $d P$. If the absolute value of $d P$ is smaller than $e$, it is considered that the output power of the PVs is operating at MPP and the program continues to the next cycle. Conversely, the controller should determine whether $d P$ is greater than zero so that it can make sure that the increment of the duty cycle is set to the same direction as the change of power $d p$. After deciding the direction of change, the controller will determine the range of step variation according to the result of $\mid d P / \alpha(k-$ $1) \mid$. If the value is large, it is thought that the change of power is mainly caused by the environmental factors and the power changes in a large range. Under these conditions, $a(k)$ is assigned to a large value so that it can respond to the requirement quickly. If the value of $|d P / \alpha(k-1)|$ is small, it is thought that the change of power is mainly caused by the adjustment of the duty cycle step, and under these conditions $a(k)$ changes in small areas so that it can change control signals smoothly. The controller keeps adjusting $D$ until $d p$ equals zero and the output power is considered to operate at MPP. Comparing with the climbing algorithm or other MPPT methods, SVSC can quickly track the MPP of PVs and reduce power jitter when the output power is near the MPP area. It also increases the antijamming capability of the system as well as the efficiency.

\section{Experimental Result}

To verify the designed system, two main experiments have been performed.

The first experiment is to verify the tracking and charging efficiency of this power system under different testing conditions. Figure 10 shows the solar strength curves that are simulated by a solar simulator under rapidly changing conditions and in a sunny day.

Figures 11 and 12 show the MPPT controller's tracking results when the solar changes rapidly. The blue curve is the simulated PV cells' ideal MPP curve. The red curve is the tracking power that is calculated by measuring MPPT 


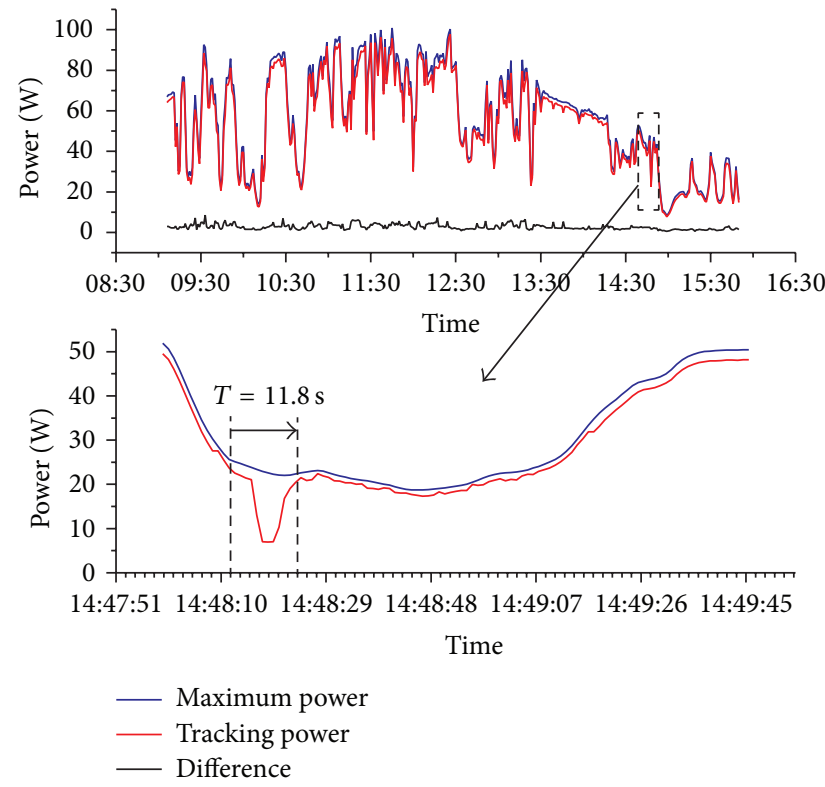

FIGURE 11: MPPT controller's tracking results under rapidly changed solar strength.

controller's output voltage and current. An inset is added to show the response time of MPPT controller in a sudden solar change from $14: 47: 51$ to $14: 49: 45$. The response time is $11.8 \mathrm{~s}$. Besides, the average difference between maximum power and tracking power is lower than $5 \mathrm{~W}$.

The efficiency of tracking is

$$
\eta=\frac{P_{t}}{P_{\text {ref }}},
$$

where $\eta$ is the efficiency of tracking, $P_{t}$ is the tracking power of MPPT controller, and $P_{\text {ref }}$ is the maximum power in an ideal case. Figure 12 shows that the efficiency of tracking is around 95\%.

Another experiment for checking the MPPT controller's tracking effect was done under the condition of a sunny day as shown in Figure 13. At 13:20 during the whole daytime test an LED load was connected to the output side. AB is the MPPT charging phase. During this period of time, the MPPT controller perfectly tracked the maximum power. The capacity of the battery is saturated at point B and then it turns to a constant voltage charging phase. The system does not work at MPP anymore. After adding an LED load at point $\mathrm{C}$, the system goes back to the MPPT phase and the battery voltage is dropped because the PV cells cannot supply enough power to the LED load. The battery is also used for supplying power to the LED. When removing the LED load at point E, after a short time of MPPT charging, the capacity of the battery is reached and it is changed to the constant voltage charging phase.

The second experiment is used to validate the control strategy of MPPT. Input power of battery which is using climbing algorithm, OCV algorithm, and SVSC algorithm

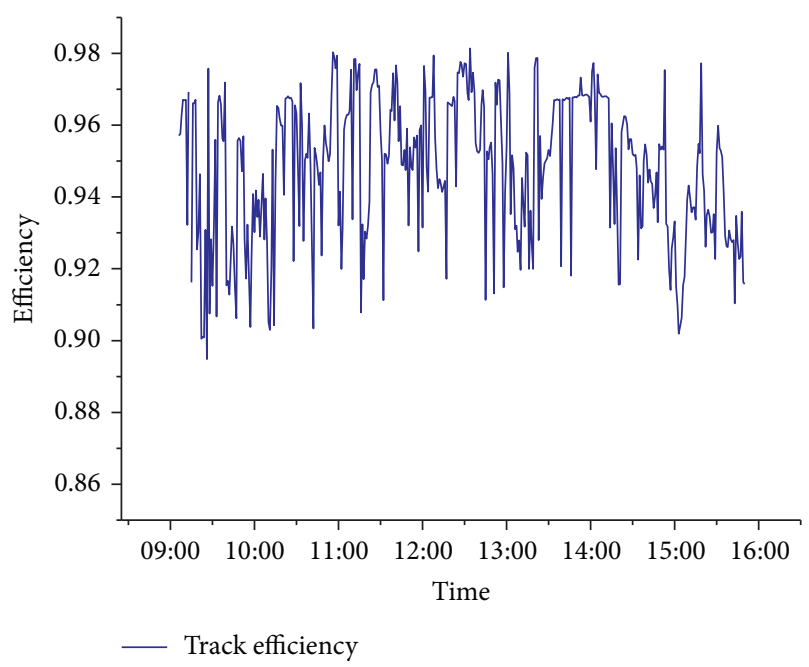

FIGURE 12: MPPT controller's tracking efficiency under rapidly changed solar strength.

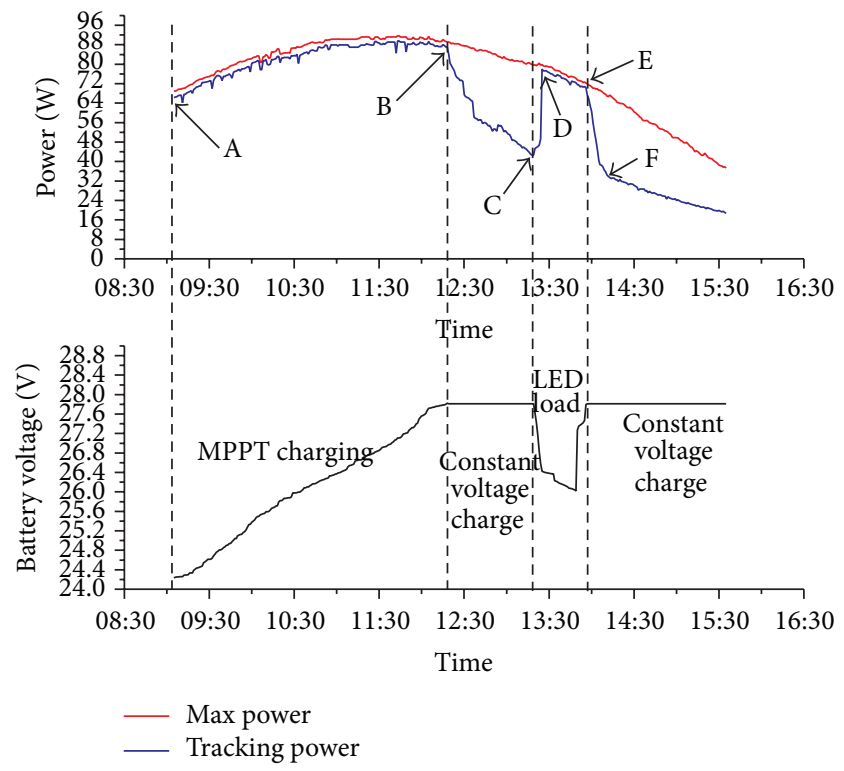

FIGURE 13: Change of MPPT controller's tracking power and battery voltage in a sunny day.

and without MPPT at different $S$ and $T$ was tested. Ten samples are chosen and the weather conditions of the experiment are shown in Table 2.

The results are shown in Figure 14. From the figure it can be seen that the input power of battery is proportional to $S$ (such as Samples 2 and 3 or Samples 8 and 9) and inversely proportional to $T$ (such as Samples 3 and 4). Both the SVSC algorithm and the climbing algorithm have good performances compared to the other two conditions, but, when the solar radiation intensity is higher than $340 \mathrm{~W} \cdot \mathrm{m}^{-2}$, SVSC has higher efficiency than the climbing algorithm (such as Samples 6, 7, 8, 9, and 10). 


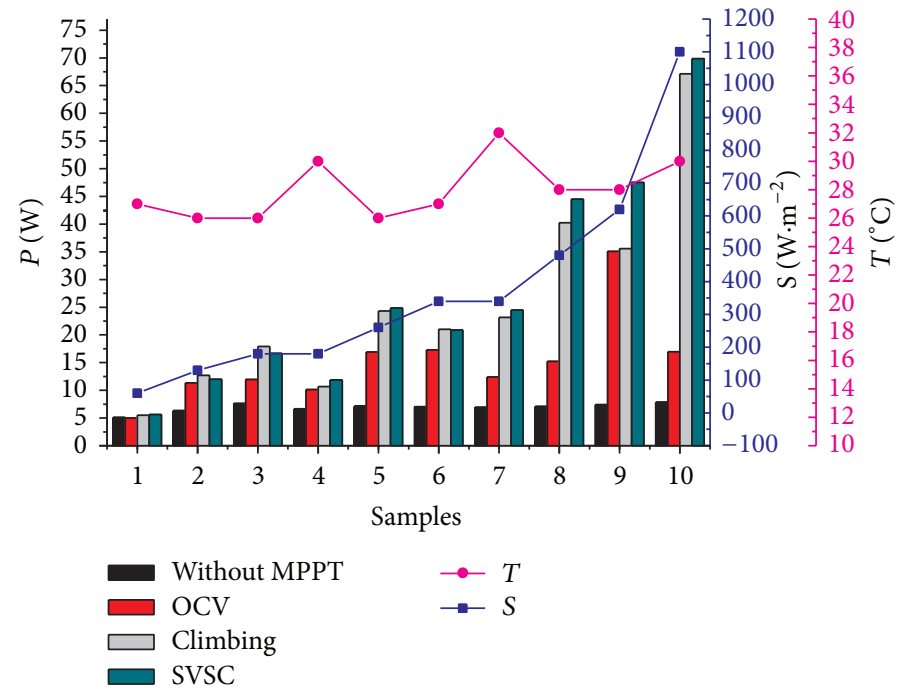

FIGURE 14: Input power of battery with different methods under different weather conditions.

TABLE 2: Weather conditions of 10 samples.

\begin{tabular}{lcc}
\hline Samples & $S\left(\mathrm{~W} \cdot \mathrm{m}^{-2}\right)$ & $T\left({ }^{\circ} \mathrm{C}\right)$ \\
\hline 1 & 60 & 27 \\
2 & 130 & 26 \\
3 & 180 & 26 \\
4 & 180 & 30 \\
5 & 260 & 26 \\
6 & 340 & 27 \\
7 & 340 & 32 \\
8 & 480 & 28 \\
9 & 620 & 28 \\
10 & 1100 & 30 \\
\hline
\end{tabular}

\section{Conclusion}

In this paper, a photovoltaic power system with MPPT functionality used for a small-size electric vehicle was designed. Test results show that this system is able to perfectly track the maximum power point of PV cells. Moreover, a novel MPPT control strategy called the SVSC algorithm was proposed. Compared to the other two algorithms, the SVSC algorithm has higher efficiency, especially when the solar radiation intensity is high.

\section{Conflict of Interests}

The authors declare that there is no conflict of interests regarding the publication of this paper.

\section{Acknowledgment}

The research work was supported by the Project of national "863 Program" named "Research and Development of MultiEnergy Distributed Power Generation System" (Project no. B21B1070540).

\section{References}

[1] H. I. Hsieh, S. F. Shih, J. H. Hsieh, and C. H. Wang, "Photovoltaic high-frequency pulse charger for lead-acid battery under maximum power point track," International Journal of Photoenergy, vol. 2013, Article ID 687693, 8 pages, 2013.

[2] W.-Y. Choi and C.-G. Lee, "Photovoltaic panel integrated power conditioning system using a high efficiency step-up DC-DC converter," Renewable Energy, vol. 41, pp. 227-234, 2012.

[3] B. Yang, W. Li, Y. Zhao, and X. He, "Design and analysis of a grid-connected photovoltaic power system," IEEE Transactions on Power Electronics, vol. 25, no. 4, pp. 992-1000, 2010.

[4] J.-M. Shen, H.-L. Jou, and J.-C. Wu, "Novel transformerless grid-connected power converter with negative grounding for photovoltaic generation system," IEEE Transactions on Power Electronics, vol. 27, no. 4, pp. 1818-1829, 2012.

[5] B. Ge, H. Abu-Rub, F. Z. Peng et al., "An energy-stored quasi-Zsource inverter for application to photovoltaic power system," IEEE Transactions on Industrial Electronics, vol. 60, no. 10, pp. 4468-4481, 2013.

[6] K. I. Hwu, W. C. Tu, and C. R. Wang, "Photovoltaic energy conversion system constructed by high step-up converter with hybrid maximum power point tracking," International Journal of Photoenergy, vol. 2013, Article ID 275210, 9 pages, 2013.

[7] R. Kadri, J.-P. Gaubert, and G. Champenois, "Nondissipative string current diverter for solving the cascaded DC-DC converter connection problem in photovoltaic power generation system," IEEE Transactions on Power Electronics, vol. 27, no. 3, pp. 1249-1258, 2012.

[8] Imtiaz, M. Abusaleh, Khan, H. Faisal, and H. Kamath, "Allin-one photovoltaic power system," IEEE Industry Applications Magazine, vol. 19, no. 4, pp. 12-23, 2013.

[9] M. Engin, "Sizing and simulation of PV-wind hybrid power system," International Journal of Photoenergy, vol. 2013, Article ID 217526, 10 pages, 2013.

[10] M. Alsayed, M. Cacciato, and G. Scarcella, "Multicriteria optimal sizing of photovoltaic-wind turbine grid connected systems," IEEE Transactions on Energy Conversion, vol. 28, no. 2, pp. 370-379, 2013. 
[11] N. C. Batista, R. Melicio, and J. C. O. Matias, "Battery Energy Storage Station (BESS)-based smoothing control of photovoltaic (PV) and wind power generation fluctuations," IEEE Transactions on Sustainable Energy, vol. 4, no. 2, pp. 464-473, 2013.

[12] Z. W. Geem, "Size optimization for a hybrid photovoltaicwind energy system," International Journal of Electrical Power \& Energy Systems, vol. 42, no. 1, pp. 448-451, 2012.

[13] M. S. Yazici, Yavasoglu, H. Ayhan, and M. Eroglu, "A mobile off-grid platform powered with photovoltaic/wind/battery/fuel cell hybrid power systems," International Journal of Hydrogen Energy, vol. 38, no. 26, pp. 11639-11645, 2013.

[14] H. A. Kazem and T. Khatib, "A novel numerical algorithm for optimal sizing of a photovoltaic/wind/diesel generator/battery microgrid using loss of load probability index," International Journal of Photoenergy, vol. 2013, Article ID 718596, 8 pages, 2013.

[15] E. Bianconi, J. Calvente, R. Giral et al., "Perturb and Observe MPPT algorithm with a current controller based on the sliding mode," International Journal of Electrical Power \& Energy Systems, vol. 44, no. 1, pp. 346-356, 2013.

[16] M. A. Elgendy, B. Zahawi, and D. J. Atkinson, "Assessment of perturb and observe MPPT algorithm implementation techniques for PV pumping applications," IEEE Transactions on Sustainable Energy, vol. 3, no. 1, pp. 21-33, 2012.

[17] G. C. Hsieh, H. I. Hsieh, and C. Y. Tsai, "Photovoltaic powerincrement-aided incremental-conductance MPPT with twophased tracking," IEEE Transactions on Power Electronics, vol. 28, no. 6, pp. 2895-2911, 2013.

[18] S. B. Kjaer, "Evaluation of the, "hill climbing" and the, "incremental conductance" maximum power point trackers for photovoltaic power systems," Transactions on Energy Conversion, vol. 27, no. 4, pp. 922-929, 2012.

[19] T. Kato, T. Miyake, D. Tashima et al., "Maximum output power control using short-circuit current and open-circuit voltage of a solar panel," Japanese Journal of Applied Physics, vol. 51, no. 10, 2012.

[20] A. A. Kulaksiz and R. Akkaya, "A genetic algorithm optimized ANN-based MPPT algorithm for a stand-alone PV system with induction motor drive," Solar Energy, vol. 86, no. 9, pp. 2366$2375,2012$.

[21] H. Mahamudul, M. Saad, and M. Ibrahim Henk, "Photovoltaic system modeling with fuzzy logic based maximum power point tracking algorithm," International Journal of Photoenergy, vol. 2013, Article ID 762946, 10 pages, 2013.

[22] B. S. Borowy and Z. M. Salameh, "Methodology for optimally sizing the combination of a battery bank and PV array in a wind/PV hybrid system," IEEE Transactions on Energy Conversion, vol. 11, no. 2, pp. 367-375, 1996. 

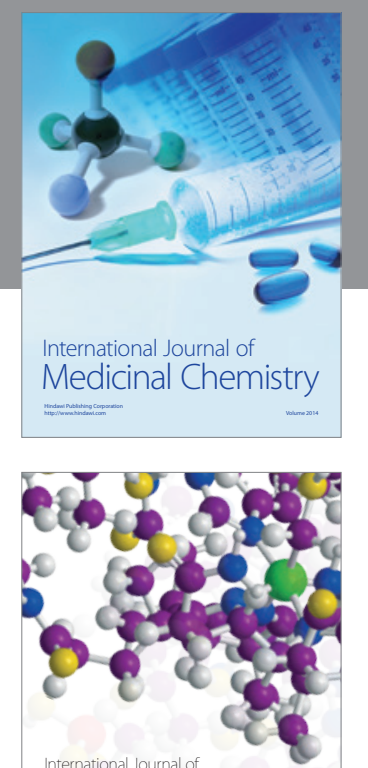

\section{Carbohydrate} Chemistry

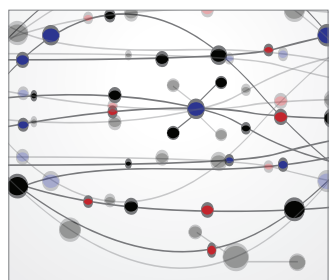

The Scientific World Journal
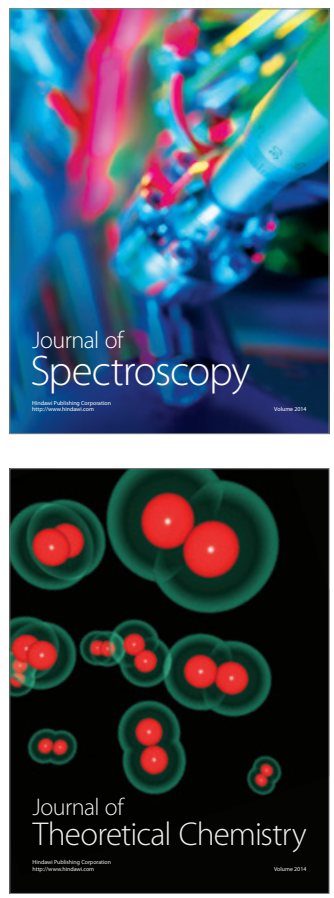
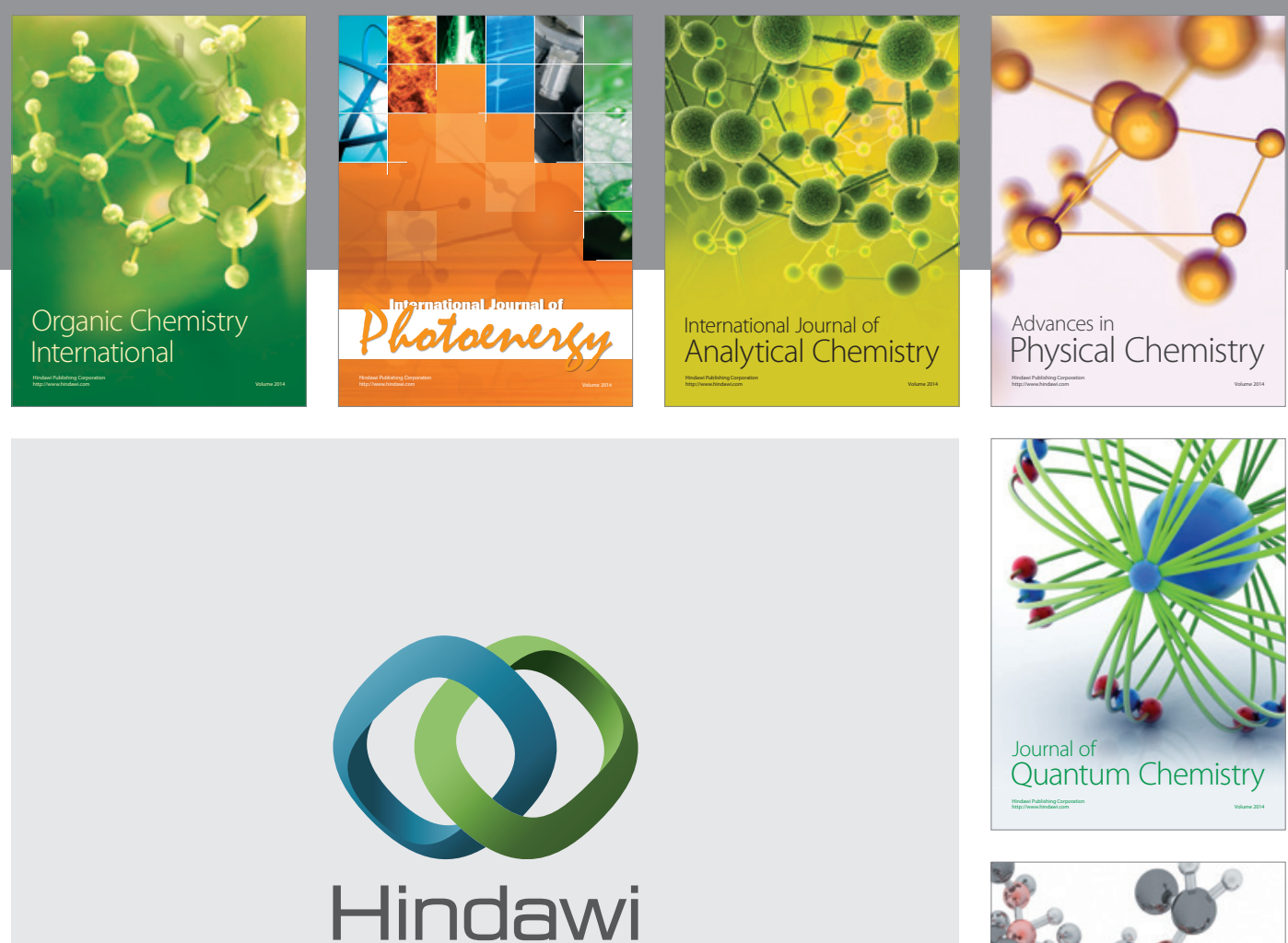

Submit your manuscripts at

http://www.hindawi.com

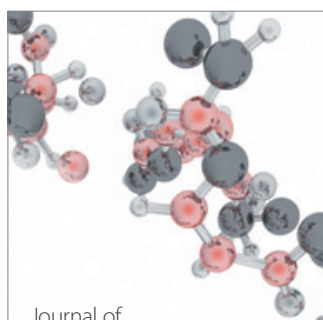

Analytical Methods

in Chemistry

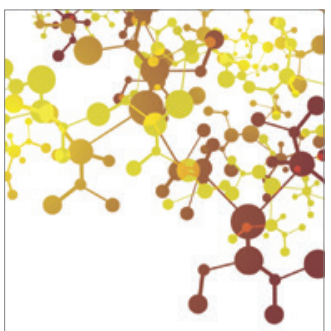

Journal of

Applied Chemistry

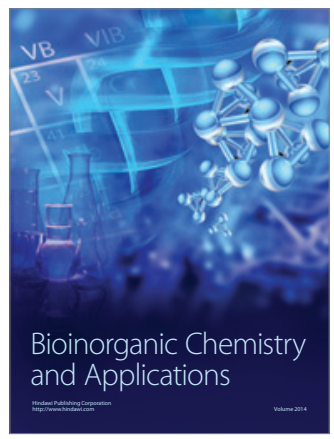

Inorganic Chemistry
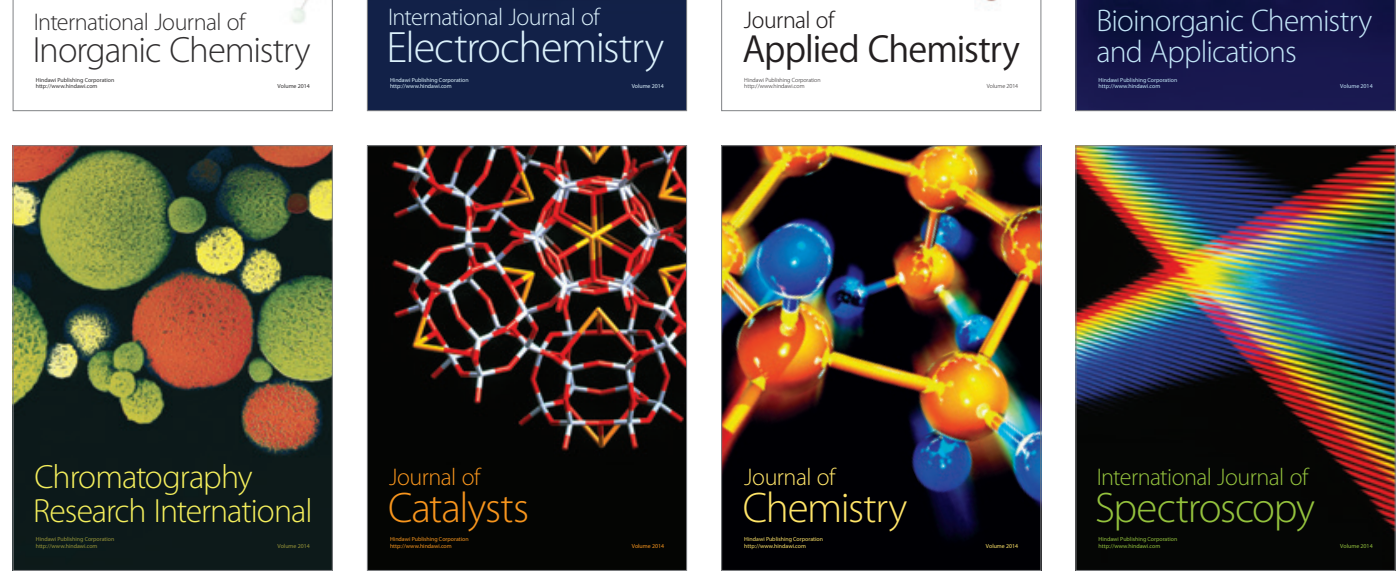